A study on the short-term effect of cafeteria diet and pioglitazone on insulin resistance and serum levels of adiponectin and ghrelin

G. Colombo, M.L. Bazzo, C.L. Nogueira, M.D.H.P. Colombo, L.L. Schiavon and A.J. d'Acampora

The Brazilian Journal of Medical and Biological Research is partially financed by

\section{惡CNPq}

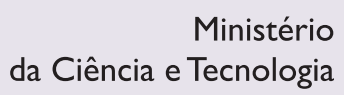

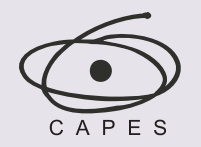

Ministério da Educação
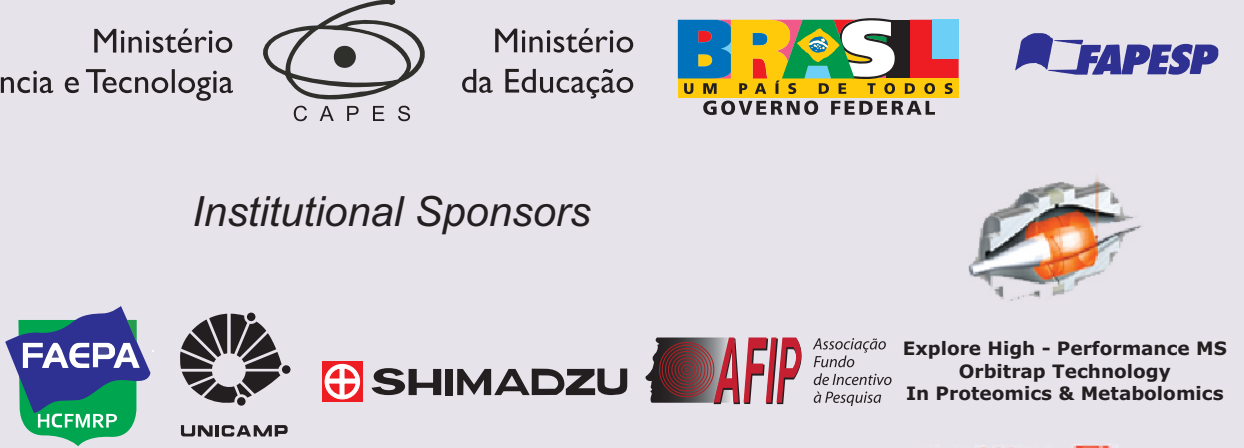

Institutional Sponsors

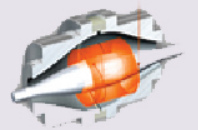

Ф SHIMADZU UNICAMP

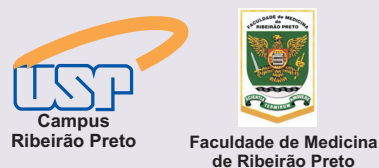

de Ribeirão Preto 


\title{
A study on the short-term effect of cafeteria diet and pioglitazone on insulin resistance and serum levels of adiponectin and ghrelin
}

\author{
G. Colombo ${ }^{1}$, M.L. Bazzo², C.L. Nogueira², M.D.H.P. Colombo ${ }^{3}$, \\ L.L. Schiavon ${ }^{1}$ and A.J. d'Acampora ${ }^{4}$ \\ ${ }^{1}$ Departamento de Clínica Médica, Hospital Universitário, Universidade Federal de Santa Catarina, \\ Florianópolis, SC, Brasil \\ 2Laboratório de Análises Clínicas, Hospital Universitário, Universidade Federal de Santa Catarina, \\ Florianópolis, SC, Brasil \\ ${ }^{3}$ Laboratório de Marcadores Celulares, Hemocentro de Santa Catarina, \\ Florianópolis, SC, Brasil \\ ${ }^{4}$ Departamento de Clínica Cirúrgica, Hospital Universitário, Universidade Federal de Santa Catarina, \\ Florianópolis, SC, Brasil
}

\begin{abstract}
The interaction between ghrelin and adiponectin is still controversial. We investigated the effect of cafeteria diet and pioglitazone on body weight, insulin resistance, and adiponectin/ghrelin levels in an experimental study on male Wistar rats. The animals were divided into four groups of 6 rats each, and received balanced chow with saline (CHOW-O) or pioglitazone $(\mathrm{CHOW}-\mathrm{P})$, or a cafeteria diet with saline (CAFE-O) or pioglitazone (CAFE-P). The chow/cafeteria diets were administered for 35 days, and saline/pioglitazone $\left(10 \mathrm{mg} \cdot \mathrm{kg}\right.$ body weight ${ }^{-1} \cdot$ day $\left.^{-1}\right)$ was added in the last 14 days prior to euthanasia. CAFE-O animals had a higher mean final weight $(372.5 \pm 21.01 \mathrm{~g})$ than CHOW-O $(317.66 \pm 25.11 \mathrm{~g}, \mathrm{P}=0.017)$ and $\mathrm{CHOW}-\mathrm{P}(322.66 \pm 28.42 \mathrm{~g}, \mathrm{P}=$ $0.035)$ animals. Serum adiponectin levels were significantly higher in CHOW-P $(55.91 \pm 20.62 \mathrm{ng} / \mathrm{mL})$ than in CHOW-O (30.52 $\pm 6.97 \mathrm{ng} / \mathrm{mL}, \mathrm{P}=0.014)$ and CAFE-O (32.54 $\pm 9.03 \mathrm{ng} / \mathrm{mL}, \mathrm{P}=0.027)$ but not in CAFE-P. Higher total serum ghrelin levels were observed in CAFE-P compared to CHOW-P animals (1.65 \pm 0.69 vs $0.65 \pm 0.36 \mathrm{ng} / \mathrm{mL}, \mathrm{P}=0.006)$. Likewise, acylated ghrelin levels were higher in CAFE-P $(471.52 \pm 195.09 \mathrm{pg} / \mathrm{mL})$ than in CHOW-P $(193.01 \pm 87.61 \mathrm{pg} / \mathrm{mL}, \mathrm{P}=0.009)$ and CAFE-O $(259.44 \pm 86.36 \mathrm{pg} / \mathrm{mL}, \mathrm{P}=0.047)$ animals. In conclusion, a cafeteria diet can lead to a significant weight gain. Although CAFE$\mathrm{P}$ animals exhibited higher ghrelin levels, this was probably related to food deprivation rather than to a direct pharmacological effect, possibly attenuating the increase in adiponectin levels.
\end{abstract}

Key words: Diet; Insulin resistance; Adiponectin; Ghrelin; Thiazolidinediones

\section{Introduction}

Increasing urbanization associated with a genotype poorly adapted to the new environment, has led humans to a global epidemic of obesity, metabolic syndrome, type 2 diabetes, and cardiovascular disease (1). Metabolic syndrome is an ensemble of some of the most powerful risk factors for cardiovascular death. The criteria for diagnosis, according to the International Diabetes Federation, are the presence of central obesity associated with two or more of the following findings: high levels of triglycerides, lower values of high-density lipoprotein (HDL) cholesterol, increased blood pressure, and elevated fasting glucose (2).
Over the past two decades, the concept of adipose tissue being an endocrine organ, which releases factors known as adipokines, has been established $(3,4)$. Examples of adipokines are: leptin, adiponectin, resistin, visfatin, apelin, vaspin, and omentin (3). Leptin and adiponectin are more closely related to insulin resistance and central obesity, and thus to the key pathophysiological aspects of the metabolic syndrome (3). Another hormone also related to insulin resistance is ghrelin, which, despite being produced mainly in the stomach, acts together with leptin and adiponectin modulating cellular sensitivity to insulin (3). 
Adiponectin was first described in 1995. The fact that its expression was found only in adipocytes, the increase in its secretion by the action of insulin, and its physiological presence in plasma suggest that it is involved in controlling the body's nutritional status (5). The secretion of adiponectin, in contrast to the secretion of other adipokines, is paradoxically decreased in obesity (6), and low basal levels of adiponectin are strong predictors of the future onset of diabetes mellitus and coronary disease in humans $(7,8)$.

Ghrelin was purified and identified in 1999 from the stomach of rats as the endogenous ligand specific for the growth hormone $(\mathrm{GH})$ secretagogue receptor (9). The stomach is the major site of ghrelin expression, synthesizing ten times more hormone per gram of tissue than the second largest source, the duodenum (10). Ghrelin appears in two major forms: acylated and non-acylated ghrelin. Acylated ghrelin seems to be the active form of ghrelin whereas non-acylated ghrelin, which is present in greater quantities than acylated ghrelin, appears to act antagonistically to the acylated form in glycemic control (11). The acylated ghrelin specifically releases $\mathrm{GH}$ both in vivo and in vitro, and $\mathrm{O}-\mathrm{n}$-octanoylation at serine 3 is essential for its activity (9). In humans, ghrelin is the only well-defined peripheral orexigenic peptide (10), and it has been shown that its levels increase during fasting and before meals, and are suppressed by food intake. The mechanisms responsible for the postprandial suppression of ghrelin are unclear, and conflicting results were found in different experiments (12). The onset of insulin resistance and compensatory hyperinsulinemia in obesity is probably the reason for the suppression of ghrelin levels (13). Ghrelin has been characterized in earlier studies as an enhancer of insulin secretion $(14,15)$, while more recent studies with mice have shown that the antagonism of its effects could promote the secretion of insulin and prevent glucose intolerance induced by a high-fat diet $(16,17)$.

The cafeteria diet represents a useful model for studies of human obesity. Even for short periods, such as two weeks, previous data obtained in Wistar rats have shown that this diet is sufficient to produce a significant increase in adiposity that appears to be more related to an increase in visceral fat than to the subcutaneous depots (18).

Pioglitazone is a drug in the thiazolidinedione class, which has been shown to have a number of metabolic actions, such as decreasing the plasma levels of triglycerides and low-density lipoproteins (LDL), increasing the size of LDL particles, increasing the concentration of HDL and decreasing hepatic lipogenesis (19). Although it has been established that the administration of pioglitazone for short periods of time to both animals and humans promotes a significant increase in adiponectin levels (20), studies about the action of the drug on ghrelin levels are scarce. The aim of the present study was to investigate the effect of the administration of a cafeteria diet and pioglitazone on body weight, insulin resistance and plasma levels of adiponectin, total ghrelin, and acylated ghrelin.

\section{Material and Methods}

\section{General design and animals}

The experiments were conducted on 24 male 60-dayold Wistar rats (250-300 g; Universidade Federal de Santa Catarina, Brazil). After the adjustment period (7 days), the animals were maintained under conditions of controlled temperature $\left(20^{\circ}\right.$ to $\left.24^{\circ} \mathrm{C}\right)$ and a 12-h day/night cycle, with lights on at 7:00 am. The animals' weight was measured with a digital scale and recorded weekly on the same day and at the same time of day, and at the time of sacrifice (Precision ${ }^{\circledR}$, PR 1000, Brazil).

The experimental procedures followed the Ethical Principles in Animal Research adopted by the Brazilian College of Animal Experimentation (COBEA) and the project was approved by the Ethics Committee on Animal Use of our institution.

The animals were randomly divided into 4 groups: 1$)$ Chow-only group ( $\mathrm{CHOW}-\mathrm{O} ; \mathrm{N}=6$ ) receiving standard rat chow (Nuvilab Cr-1 ${ }^{\circledR}$, Brazil) for 5 weeks. In the last 14 days prior to euthanasia, these animals received saline. 2) Chow-pioglitazone group ( $\mathrm{CHOW}-\mathrm{P} ; \mathrm{N}=6)$ receiving standard rat chow (Nuvilab $\mathrm{Cr}-1^{\circledR}$ ) for 5 weeks. In the last 14 days prior to euthanasia, the animals received pioglitazone. Pioglitazone was acquired from Abbott Laboratories, Brazil, and fractionated into capsules of 2.5, $3.0,3.5$, and $4.0 \mathrm{~g}$ by qualified pharmacists. The choice of the pioglitazone dose was based on a previous similar study (21) in which a significant increase of adiponectin levels was obtained without significant toxic effects on the animals. 3) Cafeteria-only group (CAFE-O; $N=6$ ) receiving a high-calorie diet (cafeteria diet) for 5 weeks. In the last 14 days prior to euthanasia, these animals received saline. 4) Cafeteria-pioglitazone group (CAFE$\mathrm{P} ; \mathrm{N}=6$ ) receiving a high-calorie diet (cafeteria diet) for 5 weeks. In the last 14 days prior to euthanasia, these animals received pioglitazone at a dose of $10 \mathrm{mg} \cdot \mathrm{kg}$ body weight $^{-1} \cdot$ day $^{-1}$.

\section{Diets and intervention}

The cafeteria diet, an animal model for studying obesity, was based on the diets used in previous studies published in the literature $(18,22)$, and consisted of blended high-energy solid foods (chocolate, toffee, donuts, stuffed cookies, bread, bacon, salami, cooked ham, fat cheese, and peanuts). The liquid part of the diet included soda and water ad libitum. The distribution of food respected a ratio of $45 \%$ carbohydrates, $45 \%$ lipids, and $10 \%$ protein per $\mathrm{kg}$ (see Table S1).

The Nuvilab Cr- $1^{\circledR}$ chow specific for rats and mice has the following composition: 22 to $22.5 \%$ crude protein, 4.4 to $4.6 \%$ lipids, and 53 to $55 \%$ carbohydrates per $\mathrm{kg}$ (see Table S2). Chow and water were provided ad libitum. Pioglitazone and saline were administered by gavage always at the same time of day (8:00 am). Fasting began $8 \mathrm{~h}$ before anesthesia. 


\section{Anesthesia and blood collection}

Prior to anesthesia, each animal received a subcutaneous injection of $0.05 \mathrm{mg} / \mathrm{kg}$ atropine to prevent excessive salivation. After identifying and weighing the animals, anesthesia was performed with a $50 \mathrm{mg} / \mathrm{kg}$ solution of ketamine associated with $10 \mathrm{mg} / \mathrm{kg}$ xylazine injected intramuscularly into the inner side of one of the hind legs.

Samples for the determination of serum glucose, insulin, ghrelin, and adiponectin were obtained by cardiac puncture after anesthesia and after an 8-h fast, and drawn into tubes with no anticoagulant. Samples for the measurement of total and acylated ghrelin were collected into a separate tube to which the protease inhibitor fluoride hydrochloride (4-(2-aminoethyl)benzenesulfonyl; Sigma Aldrich ${ }^{\circledR}$, Brazil) was added because of the instability of the hormone. After half an hour at room temperature, the collected blood was centrifuged at $3000 \mathrm{rpm}$ to obtain serum. All samples were frozen at $-70^{\circ} \mathrm{C}$ and thawed on the day of the tests. Before freezing, the serum for the measurement of total and acetylated ghrelin was acidified with hydrochloric acid to a final concentration of $0.05 \mathrm{~N}(23)$.

\section{Biochemical assays}

Blood glucose was determined using the hexokinase method of Siemens Healthcare Diagnostics Inc. ${ }^{\circledR}$, UK). Ghrelin, insulin and adiponectin levels were measured in duplicate (in triplicate if more than a $15 \%$ variation in the results was observed) using commercially available ELISA kits (Millipore ${ }^{\circledR}$, USA). The ELISAused was the sandwich type (antigen-antibody reaction). We used 450- and 590-nm filters in the spectrophotometer, and all procedures related to the analysis of biological material closely followed manufacturer instructions. For ELISA precision, see Table S3. The values of HOMA-IR (homeostasis model assessment for insulin resistance) were calculated using the following formula: HOMA-IR = fasting plasma glucose (mg/ $\mathrm{dL}) \mathrm{x}$ fasting serum insulin $(\mu \mathrm{U} / \mathrm{mL}) / 405$.

\section{Statistical analysis}

Data are reported as means \pm standard deviation. After the data were found to have normal distribution by the Shapiro-Wilk test, the comparison of the different subgroups was performed by one-way ANOVA with Bonferroni's correction. The paired $t$-test was used to compare means between different weeks of treatment in each subgroup. Statistical analysis was performed using the SPSS software version 17.0. $P$ values $<0.05$ were considered to be statistically significant.

\section{Results}

\section{Change in body weight over the weeks of the study}

As shown in Figure 1, there was a significant increase in body weight in all groups when mean final weight was compared to mean initial weight $(P<0.05)$. The mean weights of the different groups at week 3 (starting point of intervention with saline or pioglitazone) were: CHOW-O $=299.16 \pm 31.00$, CHOW $-\mathrm{P}=299.16 \pm 27.13$, CAFE-O = $351.66 \pm 12.07$, and CAFE-P $=349.16 \pm 22.62 \mathrm{~g}$. The mean final weight was as follows: $\mathrm{CHOW}-\mathrm{O}=317.66 \pm 25.11$, $\mathrm{CHOW}-\mathrm{P}=322.66 \pm 28.42, \mathrm{CAFE}-\mathrm{O}=372.50 \pm 21.01$, and CAFE-P $=345.00 \pm 35.19 \mathrm{~g}$. If we consider the starting point of intervention (pioglitazone or saline), the paired-sample $t$-test showed a trend toward significant weight gain at week 5 only for the CAFE-O group $(P=0.073)$.

Taking into account the total time of the study, the group of animals that received the cafeteria diet and saline (CAFE-O) had a higher mean final weight than the groups that received chow and saline (CHOW-O; $\mathrm{P}=0.017)$, and chow and pioglitazone ( $\mathrm{CHOW}-\mathrm{P} ; \mathrm{P}=0.035$; Figure 2).

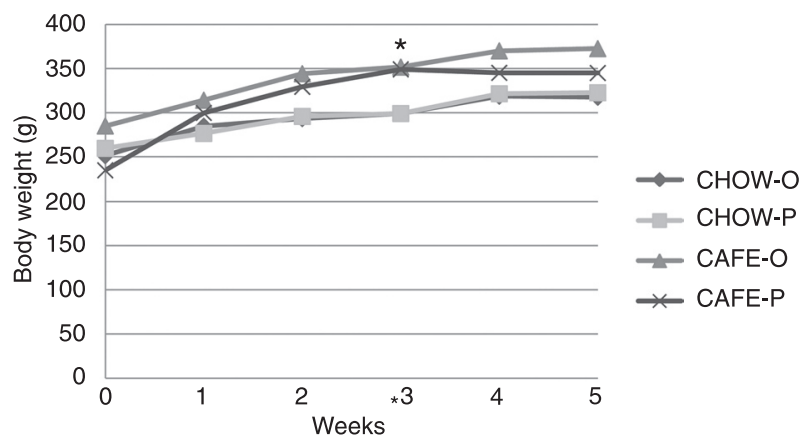

Figure 1. Body weight change in the various study groups from the beginning of the study, when the animals were 60 days old, until the day of sacrifice, when they were 95 days old. There was a significant increase in body weight in all groups when the mean final weight was compared to the mean initial weight $(P<0.05$, paired $t$-test). *Beginning of the intervention. For group definitions, see legend to Figure 2.

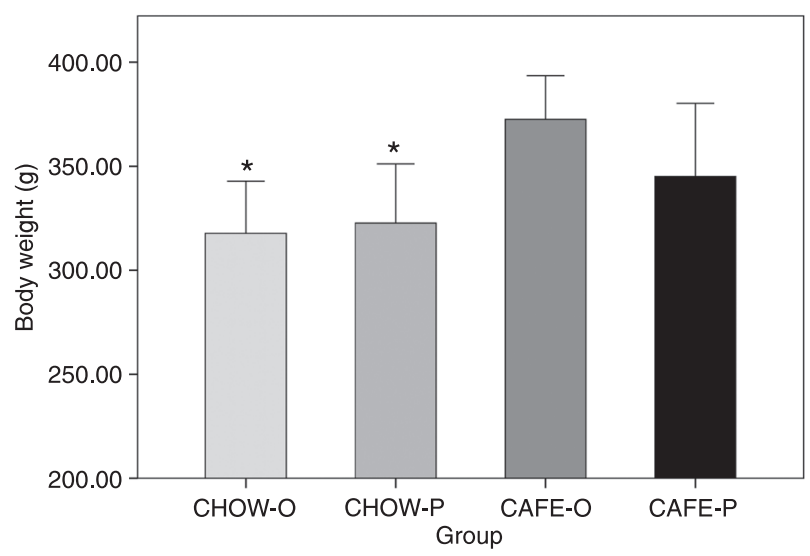

Figure 2. Body weight (means $\pm \mathrm{SD}$ ) at the end of follow-up in the chow-only (CHOW-O), chow-pioglitazone (CHOW-P), cafeteriaonly (CAFE-O), and cafeteria-pioglitazone (CAFE-P) groups. ${ }^{*} \mathrm{P}<$ 0.05 vs CAFE-O (one-way ANOVA). 
No differences were noted when the group that received cafeteria diet and pioglitazone (CAFE-P) was compared to the $\mathrm{CHOW}-\mathrm{O}$ and $\mathrm{CHOW}-\mathrm{P}$ groups regarding weight at the end of the study.

\section{Blood glucose, insulin and HOMA-IR}

As shown in Table 1, there were no differences between groups in the variables commonly used for the evaluation of insulin resistance $(P>0.05)$. No significant differences were observed for HOMA-IR comparison between the study groups $(P>0.05)$. Even groups of rats fed the cafeteria diet showed no significant differences in insulin sensitivity markers compared to the groups receiving a balanced diet for the species (chow), with higher protein and lower fat than the cafeteria diet.

\section{Adiponectin levels}

The serum adiponectin levels of each study group are reported in Table 2. CHOW-P animals had higher mean serum levels of adiponectin compared to CHOW-O ( $P=$ $0.014)$ and CAFE-O $(P=0.027)$ animals. However, no differences in adiponectin levels were observed between CAFE-P animals and the other groups.

\section{Serum levels of total and acylated ghrelin}

The total and acylated ghrelin levels of each study group are exhibited in Table 2.

A similar pattern of total and acylated ghrelin was observed for the various study groups. Higher serum levels of total ghrelin were observed in CAFE-P animals compared to
CHOW-P $(P=0.006)$, with no differences when the other groups were compared. Similarly, CAFE-P animals showed higher mean serum levels of acylated ghrelin than $\mathrm{CHOW}-\mathrm{P}$ $(P=0.009)$ and CAFE-O $(P=0.047)$ animals.

\section{Discussion}

The present study showed that rats fed a cafeteria diet and saline (CAFE-O) for 35 days have a higher increase in body weight compared to animals treated with a balanced diet. These results agree with a previous study, which demonstrated that a short period of cafeteria diet (15 days) was sufficient to lead to a significant increase in adiposity in rats, more specifically related to visceral obesity than to subcutaneous fat deposits (18). Although animals that received the cafeteria diet with pioglitazone (CAFE-P) did not exhibit higher weight gain at the end of the study when compared to those fed chow, the diarrhea observed after starting pioglitazone (week 3 ) must be considered. In addition, a potential interaction between the effects of pioglitazone and the composition of the cafeteria diet may be responsible, at least in part, for this finding.

When we evaluated the intensity of insulin resistance, no significant differences were found in blood glucose, insulin or HOMA-IR among the different groups. HOMA-IR is one of the most important parameters for the estimation of insulin resistance, providing acceptable and reliable results in rats, mice and humans (24). In the literature regarding HOMA-IR, we found studies with results similar to ours (25), and others with opposite outcomes (22).

Table 1. Blood glucose, insulin, and HOMA-IR in the chow-only group (CHOW-O), chow-pioglitazone group (CHOW-P), cafeteria-only group (CAFE-O), and cafeteria-pioglitazone group (CAFE-P).

\begin{tabular}{lcccc}
\hline Variable & CHOW-O & CHOW-P & CAFE-O & CAFE-P \\
\hline Final glucose $(\mathrm{mg} / \mathrm{dL})$ & $249.83 \pm 71.98$ & $231.16 \pm 48.39$ & $211.66 \pm 58.16$ & $219.66 \pm 86.93$ \\
Final insulin $(\mathrm{ng} / \mathrm{mL})$ & $0.31 \pm 0.30$ & $0.25 \pm 0.16$ & $0.44 \pm 0.22$ & $0.49 \pm 0.10$ \\
Final HOMA-IR $\left(\mathrm{kg} / \mathrm{m}^{2}\right)$ & $4.82 \pm 5.32$ & $2.92 \pm 1.94$ & $5.42 \pm 3.07$ & $5.76 \pm 2.26$ \\
\hline
\end{tabular}

Data are reported as means \pm SD. HOMA-IR $=$ homeostasis model assessment for insulin resistance. No statistical differences in the parameters studied were observed across the study groups $(P>0.05$, one-way ANOVA).

Table 2. Adiponectin, total ghrelin, and acylated ghrelin in the chow-only group (CHOW-O), chow-pioglitazone group (CHOW-P), cafeteria-only group (CAFE-O), and cafeteria-pioglitazone group (CAFE-P).

\begin{tabular}{lcccc}
\hline Variable & CHOW-O & CHOW-P & CAFE-O & CAFE-P \\
\hline Final adiponectin $(\mathrm{ng} / \mathrm{mL})$ & $30.52 \pm 6.97^{*}$ & $55.91 \pm 20.62$ & $32.54 \pm 9.03^{*}$ & $50.76 \pm 9.29$ \\
Final total ghrelin $(\mathrm{ng} / \mathrm{mL})$ & $1.15 \pm 0.29$ & $0.65 \pm 0.36^{+}$ & $1.21 \pm 0.34$ & $1.65 \pm 0.69$ \\
Final acylated ghrelin $(\mathrm{pg} / \mathrm{mL})$ & $268.48 \pm 78.97$ & $193.01 \pm 87.61^{+}$ & $259.44 \pm 86.36^{+}$ & $471.52 \pm 195.09$ \\
\hline
\end{tabular}

Data are reported as means $\pm \mathrm{SD}$. * $\mathrm{P}<0.05$ vs CHOW-P; ${ }^{+} \mathrm{P}<0.05$ vs CAFE-P (one-way ANOVA). 
In the current study, no differences were observed in adiponectin levels when animals that received only chow (CHOW-O) were compared to those fed the cafeteria diet (CAFE-O) without the influence of pioglitazone. Similarly, a previous experimental study in rats showed no differences in total serum adiponectin levels when the balanced diet group was compared to that receiving the cafeteria diet for 15 days. However, when adiponectin titers were adjusted for the white adipose tissue mass (adiponectin/total white adipose tissue), serum adiponectin levels were found to be lower in the cafeteria diet group (26). Although white adipose tissue was not measured in the present study, we may speculate that adiponectin levels were disproportionately low in the cafeteria-only group $(18,22)$.

Higher serum levels of adiponectin at the end of the study were observed in animals receiving chow plus 14 days of pioglitazone ( $\mathrm{CHOW}-\mathrm{P}$ ) compared to the non-pioglitazone groups (CHOW-O and CAFE-O). This finding confirms other studies in the literature, in which the administration of pioglitazone for short periods of time both to animals and humans promoted an acutely significant increase in adiponectin levels $(20,27,28)$. As a member of the thiazolidinediones, pioglitazone exhibits agonistic effects on the peroxisome proliferator-activated-receptor gamma, which, when activated, stimulates the transcription of the gene for adiponectin (29). Although a numerical increase in adiponectin levels was observed in animals that received pioglitazone and the cafeteria diet (CAFE-P), no statistical significance was reached. A possible explanation for this attenuation in the ability of pioglitazone to raise serum levels of adiponectin could be the higher levels of ghrelin observed in this group of animals. As previously demonstrated in the literature, administration of ghrelin can decrease the expression of the adiponectin gene in adipose tissue and, consequently, suppress the serum levels of this adipokine (30).

When we compared the non-pioglitazone groups (CHOW-O and CAFE-O), no differences in serum levels of total or acylated ghrelin were noted. Total ghrelin, which is the sum of acylated and non-acylated isoforms of ghrelin, seems to have a reasonable relationship with the acylated form since both levels are constant under various conditions that affect the physiology of the hormone (31). Considering the findings of previous studies showing that low ghrelin titers in obese individuals are not associated with increased body mass index per se, but with higher degrees of insulin resistance $(13,32)$, the most likely finding in animals fed a cafeteria diet would be an increase in insulin resistance, with decreased levels of ghrelin. However, the present study was not able to show an increase of insulin resistance in those animals.

Higher serum levels of acylated ghrelin were observed in animals receiving the cafeteria diet with pioglitazone compared to those receiving chow with pioglitazone and the cafeteria diet without pioglitazone. These findings could be explained by the stabilization of weight after an upward curve of weight gain in animals that received the cafeteria diet and pioglitazone. This pattern of weight curve could be related to a spontaneous low food intake triggered by the peculiarities of the high-fat cafeteria diet and the development of diarrhea after intervention with pioglitazone. The lipid-enriched diet has been associated with hypophagia by various mechanisms, including delayed gastric emptying (33), increased oxidation of lipids (33,34), and increased secretion of cholecystokinin by the pancreas (35). Additionally, pioglitazone is related to the onset of nausea and diarrhea as adverse effects (36), reducing even more food intake. As already demonstrated in the literature, food deprivation is physiologically associated with increased plasma levels of ghrelin, and may be responsible for the higher serum acylated ghrelin levels observed in the cafeteria/pioglitazone group (12).

We acknowledge some limitations of our analysis. First, the period of exposure to the cafeteria diet or chow may have been insufficient for the development of laboratory findings associated with insulin resistance. However, even though data about the impact of longer periods of the cafeteria diet on insulin resistance parameters would be of interest, this was not the aim of the present study. Second, food intake was not controlled, but food intake control was not directly related to the objective of the study. Third, to explain the stabilization of weight gain in the animals receiving the cafeteria diet and pioglitazone we infer that this may have been caused by a change of feeding behavior (food deprivation) due to the high-fat diet, associated with adverse drug effects, but we cannot definitively prove this assumption. However, the most important aspect is the weight variation of the different groups of animals, and not necessarily the reason for it. Fourth, the absence of body fat measurement may have limited the characterization of the expansion of visceral adipose tissue, and may have prevented the assessment of the ratio of adiponectin and white adipose tissue. Nevertheless, previous studies have already validated the cafeteria diet as an inducer of expansion of adipose tissue, especially visceral adipose tissue $(18,22)$.

Finally, more sensitive tools for the estimate of insulin sensitivity might have been useful in evaluating insulin resistance among the study groups. As described previously, the hyperinsulinemic euglycemic clamp, which was not used in this study, provides the best and purest information about the tissue action of insulin (37). HOMA-IR, as applied in this study, is currently considered to be a simple and reliable index for measuring the degree of insulin resistance, and is closely related to the euglycemic hyperinsulinemic clamp, which is technically difficult in rats due to the small caliber of vessels and smaller blood volume (24).

In conclusion, the cafeteria diet is a useful model for the study of human obesity. Pioglitazone is a potent stimulator of circulating levels of adiponectin. This study helps us understand more about the relationship between adiponectin and ghrelin, two hormones related to energy balance in the 
body. The apparent attenuation of the effect of pioglitazone by ghrelin in increasing adiponectin levels suggests that ghrelin really suppresses adiponectin. This is particularly important since we already have a drug used in clinical practice (pioglitazone) that exerts its effect by increasing adiponectin levels. Despite the apparent importance of the relationship between these two hormones, we found only one article in the literature that addressed this interaction, demonstrating that the administration of ghrelin suppresses the expression of the adiponectin gene in adipose tissue.

\section{References}

1. Zimmet P, Thomas CR. Genotype, obesity and cardiovascular disease - has technical and social advancement outstripped evolution? J Intern Med 2003; 254: 114-125.

2. International Diabetes Federation. The IDF consensus worldwide definition of the metabolic syndrome. Brussels: International Diabetes Federation; 2006.

3. Schutte AE, Huisman HW, Schutte R, van Rooyen JM, Malan L, Fourie CM, et al. Adipokines and cardiometabolic function: How are they interlinked? Regul Pept 2010; 164: 133-138.

4. Chandran M, Phillips SA, Ciaraldi T, Henry RR. Adiponectin: more than just another fat cell hormone? Diabetes Care 2003; 26: 2442-2450.

5. Scherer PE, Williams S, Fogliano M, Baldini G, Lodish HF. A novel serum protein similar to $\mathrm{C} 1 \mathrm{q}$, produced exclusively in adipocytes. J Biol Chem 1995; 270: 26746-26749.

6. Hajer GR, van Haeften TW, Visseren FL. Adipose tissue dysfunction in obesity, diabetes, and vascular diseases. Eur Heart J 2008; 29: 2959-2971.

7. Maahs DM, Ogden LG, Kinney GL, Wadwa P, Snell-Bergeon JK, Dabelea D, et al. Low plasma adiponectin levels predict progression of coronary artery calcification. Circulation 2005; 111: 747-753.

8. Mather KJ, Funahashi T, Matsuzawa Y, Edelstein S, Bray GA, Kahn SE, et al. Adiponectin, change in adiponectin, and progression to diabetes in the Diabetes Prevention Program. Diabetes 2008; 57: 980-986.

9. Kojima M, Hosoda H, Date Y, Nakazato M, Matsuo H, Kangawa K. Ghrelin is a growth-hormone-releasing acylated peptide from stomach. Nature 1999; 402: 656-660.

10. Cummings DE, Foster-Schubert KE, Overduin J. Ghrelin and energy balance: focus on current controversies. Curr Drug Targets 2005; 6: 153-169.

11. van der Lely AJ. Ghrelin and new metabolic frontiers. Horm Res 2009; 71 (Suppl 1): 129-133.

12. Cordido F, Isidro ML, Nemina R, Sangiao-Alvarellos S. Ghrelin and growth hormone secretagogues, physiological and pharmacological aspect. Curr Drug Discov Technol 2009; 6: 34-42.

13. McLaughlin T, Abbasi F, Lamendola C, Frayo RS, Cummings DE. Plasma ghrelin concentrations are decreased in insulin-resistant obese adults relative to equally obese insulin-sensitive controls. J Clin Endocrinol Metab 2004; 89: 1630-1635.

14. Date $Y$, Nakazato M, Hashiguchi S, Dezaki K, Mondal MS, Hosoda $\mathrm{H}$, et al. Ghrelin is present in pancreatic alpha-cells

\section{Supplementary material}

Table S1

Table S2

Table S3

\section{Acknowledgments}

The funds for the purchase of the testing kits were provided by Universidade Federal de Santa Catarina (UFSC) of humans and rats and stimulates insulin secretion. Diabetes 2002; 51: 124-129.

15. Lee HM, Wang G, Englander EW, Kojima M, Greeley GH Jr. Ghrelin, a new gastrointestinal endocrine peptide that stimulates insulin secretion: enteric distribution, ontogeny, influence of endocrine, and dietary manipulations. Endocrinology 2002; 143: 185-190.

16. Dezaki K, Kakei M, Yada T. Ghrelin uses Galphai2 and activates voltage-dependent $\mathrm{K}^{+}$channels to attenuate glucoseinduced $\mathrm{Ca}^{2+}$ signaling and insulin release in islet beta-cells: novel signal transduction of ghrelin. Diabetes 2007; 56: 2319-2327.

17. Dezaki K, Sone H, Koizumi M, Nakata M, Kakei M, Nagai H, et al. Blockade of pancreatic islet-derived ghrelin enhances insulin secretion to prevent high-fat diet-induced glucose intolerance. Diabetes 2006; 55: 3486-3493.

18. Rodriguez E, Ribot J, Rodriguez AM, Palou A. PPAR-gamma2 expression in response to cafeteria diet: gender- and depot-specific effects. Obes Res 2004; 12: 1455-1463.

19. Beysen C, Murphy EJ, Nagaraja H, Decaris M, Riiff T, Fong A, et al. A pilot study of the effects of pioglitazone and rosiglitazone on de novo lipogenesis in type 2 diabetes. $J$ Lipid Res 2008; 49: 2657-2663.

20. Pereira RI, Leitner JW, Erickson C, Draznin B. Pioglitazone acutely stimulates adiponectin secretion from mouse and human adipocytes via activation of the phosphatidylinositol 3'-kinase. Life Sci 2008; 83: 638-643.

21. Liu X, Luo D, Zheng M, Hao Y, Hou L, Zhang S. Effect of pioglitazone on insulin resistance in fructose-drinking rats correlates with AGEs/RAGE inhibition and block of NADPH oxidase and NF kappa B activation. Eur J Pharmacol 2010; 629: 153-158.

22. Sampey BP, Vanhoose AM, Winfield HM, Freemerman AJ, Muehlbauer MJ, Fueger PT, et al. Cafeteria diet is a robust model of human metabolic syndrome with liver and adipose inflammation: comparison to high-fat diet. Obesity 2011; 19: 1109-1117.

23. Hosoda H, Doi K, Nagaya N, Okumura H, Nakagawa E, Enomoto $\mathrm{M}$, et al. Optimum collection and storage conditions for ghrelin measurements: octanoyl modification of ghrelin is rapidly hydrolyzed to desacyl ghrelin in blood samples. Clin Chem 2004; 50: 1077-1080.

24. Mather K. Surrogate measures of insulin resistance: of rats, mice, and men. Am J Physiol Endocrinol Metab 2009; 296: E398-E399.

25. Naderali EK, Pickavance LC, Wilding JP, Williams G. Diet- 
induced endothelial dysfunction in the rat is independent of the degree of increase in total body weight. Clin Sci 2001; 100: 635-641.

26. Ribot J, Rodriguez AM, Rodriguez E, Palou A. Adiponectin and resistin response in the onset of obesity in male and female rats. Obesity 2008; 16: 723-730.

27. Yang G, Li L, Tang Y, Boden G. Short-term pioglitazone treatment prevents free fatty acid-induced hepatic insulin resistance in normal rats: possible role of the resistin and adiponectin. Biochem Biophys Res Commun 2006; 339: 1190-1196.

28. Ikeda $Y$, Takata H, Inoue K, Shinahara M, Inada S, Maruyama $\mathrm{H}$, et al. Pioglitazone rapidly increases serum adiponectin levels in men with normal glucose tolerance. Diabetes Care 2007; 30: e48.

29. Phillips SA, Kung JT. Mechanisms of adiponectin regulation and use as a pharmacological target. Curr Opin Pharmacol 2010; 10: 676-683.

30. Ott V, Fasshauer M, Dalski A, Meier B, Perwitz N, Klein HH, et al. Direct peripheral effects of ghrelin include suppression of adiponectin expression. Horm Metab Res 2002; 34: 640-645.

31. Murakami N, Hayashida T, Kuroiwa T, Nakahara K, Ida T, Mondal MS, et al. Role for central ghrelin in food intake and secretion profile of stomach ghrelin in rats. $J$ Endocrinol 2002; 174: 283-288.

32. Williams DL, Cummings DE. Regulation of ghrelin in physiologic and pathophysiologic states. J Nutr 2005; 135: 13201325.

33. Ebal E, Cavalie H, Michaux O, Lac G. Effect of a lipidenriched diet on body composition and some regulatory hormones of food intake in growing rats. Ann Endocrinol 2007; 68: 366-371.

34. Ramirez I. Hypophagia following dietary obesity. Physiol Behav 1986; 38: 95-98.

35. Bueno AA, Oyama LM, de Oliveira C, Pisani LP, Ribeiro EB, Silveira VL, et al. Effects of different fatty acids and dietary lipids on adiponectin gene expression in 3T3-L1 cells and C57BL/6J mice adipose tissue. Pflugers Arch 2008; 455: 701-709.

36. Kasliwal R, Wilton LV, Shakir SA. Monitoring the safety of pioglitazone: results of a prescription-event monitoring study of 12,772 patients in England. Drug Saf 2008; 31: 839-850.

37. Hughey CC, Hittel DS, Johnsen VL, Shearer J. Hyperinsulinemic-euglycemic clamp in the conscious rat. $J$ Vis Exp 2011; 48: doi: 10.3791/2432. 